\title{
Tinea Corporis Resolution by Homoeopathy: A Case Report
}

\author{
Zeba Waheed $^{1}$, Ram Krishna Ghosh ${ }^{2}$, Aniruddha Banerjee ${ }^{3}$ \\ ${ }^{1}$ Postgraduate Trainee, Dept. of Case Taking and Repertory, National Institute of Homoeopathy, Govt. of India \\ ${ }^{2}$ Lecturer \& Head, Dept. of Surgery, National Institute of Homoeopathy, Govt. of India \\ ${ }^{3}$ Assistant Professor, Dept. of Obstetrics \& Gynaecology, Midnapore Homoeopathic Medical College \& \\ Hospital, Govt. of West Bengal \\ Corresponding Author: Aniruddha Banerjee
}

\begin{abstract}
Dermatophytes, the most common causative agents, are assuming high significance in developing countries like India. These organisms metabolise keratin and cause a range of pathologic clinical presentations, including tinea pedis, tinea corporis, tinea cruris, etc. Although usually painless and superficial, these fungi can behave in an invasive manner, causing deeper and disseminated infection and should not be neglected. The lesions may become widespread and may have significant negative social, psychological, and occupational health effects, and can compromise the quality of life significantly. The recent prevalence of dermatophytosis in India ranges from 36.6-78.4\%. Currently, dermatologists across India are inundated with cases of dermatophytosis presenting with unusual large lesions, ring within ring lesions, multiple site lesions (tinea cruris et corporis), and corticosteroid modified lesions, making diagnosis a difficult bet. ${ }^{1}$ First line of therapy has always been a topical agent; while in resistance of the topical agents next preferred treatment are the oral therapies of antifungal agents (Ketoconazole, Terbinafine, Fluconazole and Itraconazole). However complementary and alternative therapy has also shown the significant results in control of growth of these dermatophytes. Homoeopathy has always been a safe and cost effective treatment in cases of dermatophyte infections. ${ }^{2}$ The present case report of a 31 years old Muslim female, Sepia officinalis $1 \mathrm{M}$ and Sulphur (30C and 200C) have shown marked improvement in the reduction of the lesion.
\end{abstract}

Keywords: Tinea corporis, homoeopathy, totality of symptoms, repertorisation.

\section{INTRODUCTION}

The skin or the integument is the external organ that protects against the mechanical trauma, UV light and infection. ${ }^{3}$ Dermatophytosis, also known as ringworm or tinea, is a chronic fungal infection of the skin, hair or nails. ${ }^{4}$ Trichophyton, Epidermophyton and Microsporum are responsible for this group of dermatophyte infections. ${ }^{5}$ Tinea corporis is characterized by annular or arcuate lesion with relatively clearing in the centre and an active periphery. It is infection of the glabrous skin except palm, soles and groins. The general management includes keeping the area dry and avoiding the use of synthetic clothes. ${ }^{6}$
Histologically, fungal hyphae and arthropores of dermatophytes are present in the stratum corneum of the skin, nails and hair. Hyphae may be septate and nonseptate. Spores are round to oval bodies which grow by budding. Periodic Acid Schiff (PAS) reactions which stains the fungi deep pink to red and methenamine silver nitrate method that stains fungi black. $^{3}$

Homoeopathy signifies a system of treatment in which the prescription is based on the similarity of symptoms of the patient, to those of a drug as obtained during proving of the drug on healthy human beings. The great advantage of considering 
disease as nothing but the totality of symptoms is that we are not to wait for the structural changes to occur for treating the patients. It is not correct to presume that "homoeopathy removes the symptoms but the disease remains." If the totality of symptoms is removed entirely, there cannot be any more disease hidden in the interior. ${ }^{7}$

\section{CASE PROPER}

\section{Patient details:}

A 31-year old Muslim female of fair and flabby constitution belonging to a middle socio- economic status reported at NIH OPD with red eruptions in circular pattern with reddish discolouration on forearm, inframammary region and back of neck for 2 years. There was burning and itching present at the site of the lesion which was aggravated in afternoon, evening and cold air while get ameliorated in warmth of bed. The associated complaint was bleeding hemorrhoids since 1 month.

\section{Totality of symptoms:}

1. Indifference towards family members

2. Indolent in doing her work

3. Stool: hard, unsatisfactory

4. Eruptions with itching and burning

5. Itching < evening

6. Itching > warmth of bed

Timeline: The duration of treatment was 5months. Patient came to the Outpatient Department on 17/11/2020 with evidence of Tinea Corporis and improvement was seen on $13 / 4 / 2021$.

\section{Repertorial sheet: ${ }^{8,9}$}

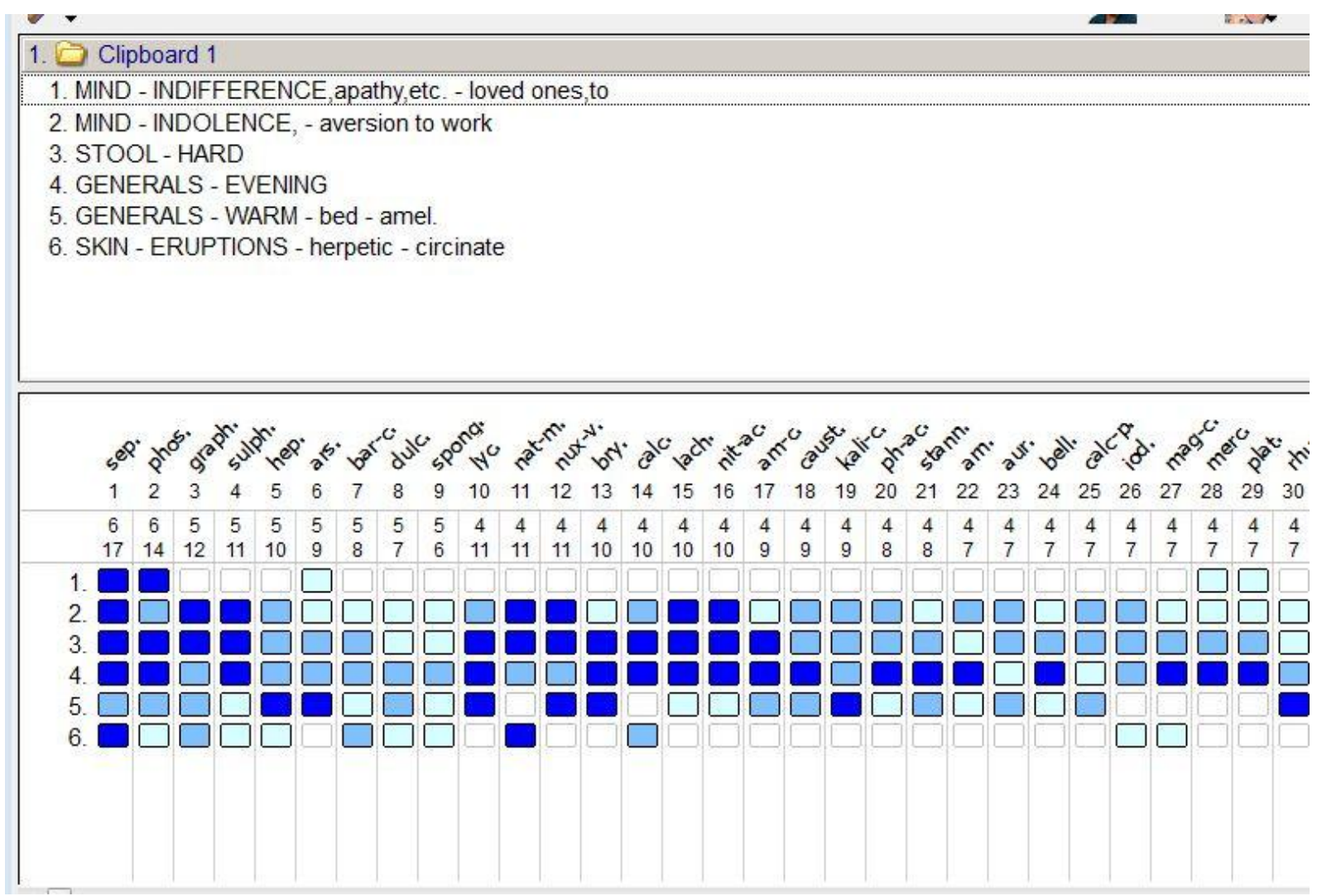

\section{RESULT}

After repertorisation process with Kent's repertory, Sepia officinalis covered the maximum number (6) with maximum marks (17). After consultation with the homoeopathic materia medica, it was prescribed which gave the grave result. 


\section{Prescription}

On the totality of symptoms, Sepia officinalis $1 \mathrm{M} / 1$ dose was prescribed; no haemorrhoidal bleeding was seen but the itching showed amelioration for few days then aggravation. Placebo was given for a month. No improvement seen. After going through the lines of Allen's keynotes as written, "if complaints are continuously relapsing, patient seems to get almost well when the disease return again and again" Sulphur 30, 1 dose was prescribed and the lesion started disappearing. ${ }^{10}$ On the $6^{\text {th }}$ visit, Sulphur 200/ 1dose was prescribed showing the Kent's degree of series and the patient showed no itching, burning or any new eruptions.

\section{FOLLOW UPS:}

\begin{tabular}{|l|l|l|l|}
\hline Sr. No. & Date & Medicine & Follow ups \\
\hline 1. & $17 / 11 / 2020$ & Sepia officinalis 1M/1dose & - \\
\hline 2. & $27 / 11 / 2020$ & Placebo & Bleeding decreased, itch increased \\
\hline 3. & $10 / 12 / 2020$ & Sulphur 30/1 dose & - \\
\hline 4. & $13 / 2 / 2021$ & Placebo & Itching decreased \\
\hline 5. & $9 / 3 / 2021$ & Placebo &, \\
\hline 6. & $7 / 4 / 2021$ & Sulphur 200/1dose &, \\
\hline 7. & $13 / 4 / 2021$ & Placebo &, \\
\hline
\end{tabular}
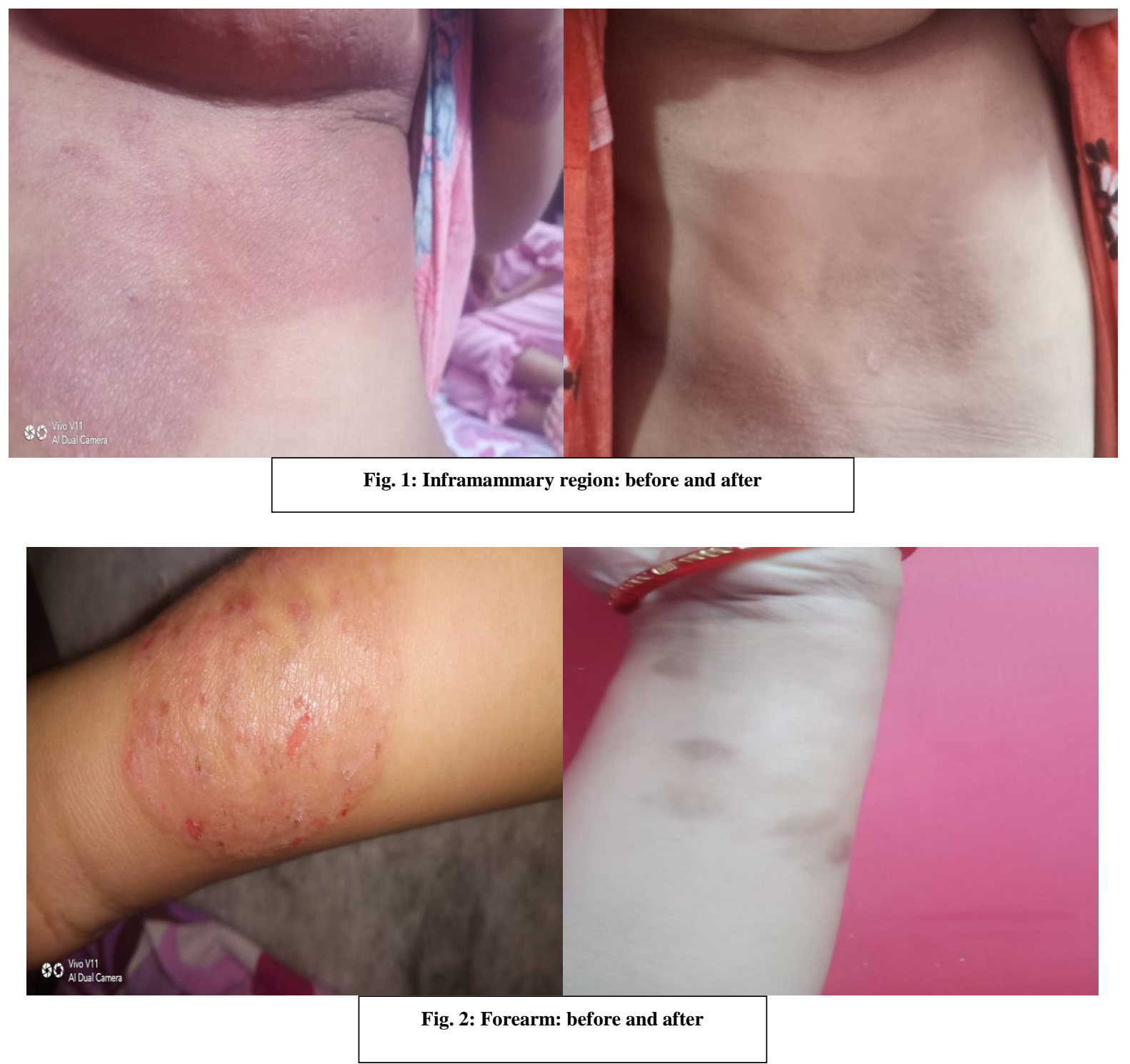


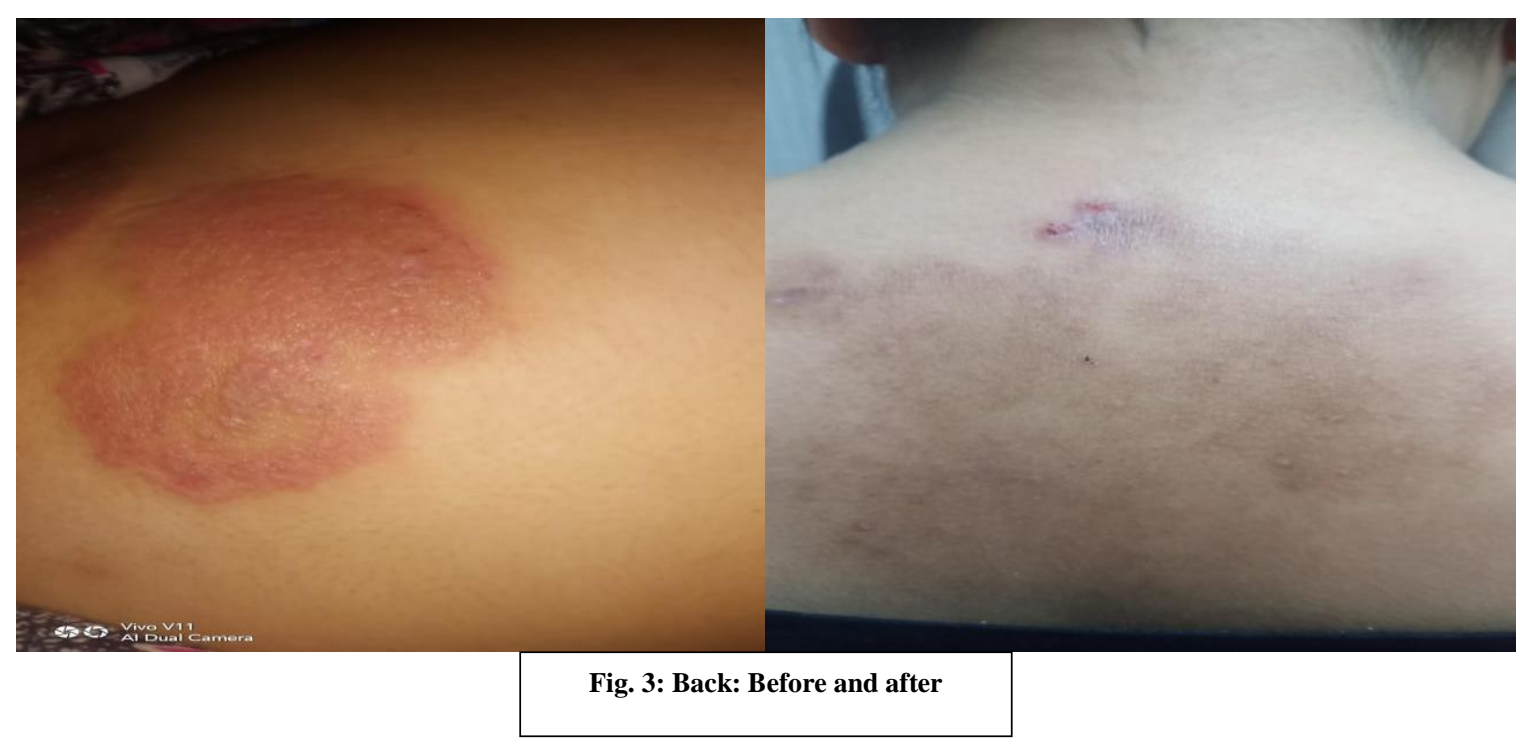

\section{DISCUSSION}

The patient presented with red eruptions in circular pattern with reddish discoloration on forearm, inframammary region and back of neck for 2 years. There was no family history of Tinea Corporis or other benign skin disease in the family. This case treated with individualized homoeopathic medicine showed complete resolution of reddish discoloration on forearm, inframammary region and back of neck without any recurrence in a follow up period. As there is no effective treatment in conventional medicine, a substantial number of Tinea patients resort to Complementary and Alternative Medicine (CAM). Patient's choice of treatment gave positive response through homoeopathic treatment.

In this case, Sepia Officinalis $1 \mathrm{M}$ was selected as a 'Similimum' on the basis of totality of symptoms followed by repertorial analysis and consultation with Homoeopathic Materia Medica which was given more priority in this case. After seeing the case again, Sulphur 30, 1 dose was prescribed and the lesion started disappearing. Finally, Sulphur 200/ 1dose was prescribed showing the Kent's degree of series and the patient showed no itching, burning or any new eruptions. So the treatment outcome of resolution of Tinea Corporis making it clinically almost subside was highly satisfactory. Thus, the outcome of this case of Tinea Corporis of the lady indicates the beneficial treatment effect by an individualized homoeopathic medicine.

\section{CONCLUSION}

This case report suggests homoeopathic treatment as a promising complementary or alternative therapy and emphasizes the need of repertorisation in individualized homoeopathic prescription. This case shows a positive role of Homoeopathy in treating Tinea Corporis. However, this is a single case study and requires well designed studies which may be taken up for future scientific validation.

\section{Acknowledgement: None}

\section{Conflict of Interest: None}

\section{Source of Funding: None}

\section{REFERENCES}

1. Rajagopalan M.,Inmadar A., et al.,Expert Consensus on The Management of Dermatophytosis in India (ECTODERM India), BMC Dermatology, 24 July, 2018.

2. Uttamchandani P.A., Patil A.D., Homoeopathy an Alternative Therapy for Dermatophyte Infections, International Journal of Health Sciences and Research, January 2019, P: 316-320 
3. Mohan H. Textbook of pathology. Jaypee Brothers Medical Publishers; 2015.

4. L KD, L HS, L JJ, S FA, L LD, J L. Harrison's Principles of Internal Medicine. In L KD, L HS, L JJ, S FA, L LD, J L, editors. Harrison's Principles of Internal Medicine. 16th New Delhi: McGraw-Hill Education; 2005.

5. Marks R., Motley R., Roxburgh's Common Skin Diseases, $18^{\text {th }}$ edition, 2015

6. Khanna N., Illustrated Synopsis of Dermatology and Sexually Transmitted Disease, Elsevier, $5^{\text {th }}$ edition, 2016.

7. Dey S. Essentials of Practice and Practice of Homoeopathy. 3rd ed. Kolkata: Smt. Aparna Bhattacharya; 2009.
8. RADAR 10 Computer Software

9. Kent J.T. Repertory of the Homoeopathic Materia Medica, B. Jain Publishers (P) LTD, NOIDA, U.P. (INDIA) 2002.

10. Allen H. Keynotes and Characteristics with Comparisons of some of the Leading Remedies of the Materia Medica with Bowel Nosodes. 8th ed. New Delhi: B. Jain; 1999.

How to cite this article: Waheed Z., Ghosh R.K., Banerjee A. Tinea corporis resolute by homoeopathy: a case report. Int J Health Sci Res. 2021; 11(6): 135-139. DOI: https://doi. org/10.52403/ijhsr.20210619 